\title{
ULTRA LOW POWER HYBRID MICRO ENERGY HARVESTER USING RF, THERMAL AND VIBRATION FOR BIOMEDICAL DEVICES
}

\author{
JAHARIAH SAMPE*, FARAH FATIN ZULKIFLI, NOR AFIDATUL ASNI SEMSUDIN, MD SHABIUL ISLAM, \\ BURHANUDDIN YEOP MAJLIS
}

Institute of Microengineering and Nanoelectronics (IMEN), Universiti Kebangsaan Malaysia, 43600, Bangi, Selangor

Email: jahariah@ukm.edu.my

Received: 24 Apr 2016 Revised and Accepted: 29 May 2016

\begin{abstract}
The objective of this research is to design ultra-low power Hybrid Micro Energy Harvester (HMEH) circuit using hybrid inputs of radio frequency (RF), thermal and vibration for biomedical devices. In the HMEH architecture, three input sources (RF, thermal and vibration) are combined in parallel to solve the limitation issue of a single source energy harvester and to improve the system performance. Energy will be scavenged from the human body for thermal and vibration sources by converting directly temperature difference and human movement to electrical energy. The inputs are set to $0.02 \mathrm{~V}$ and $0.5 \mathrm{~V}$ for thermal and vibration respectively with the frequency of $1 \mathrm{kHz}$. Meanwhile, RF source is absorbed from radio wave propagation in our surrounding. For this work, the frequency is set to $915 \mathrm{MHz}$ and the output voltages for input ranges of $-20 \mathrm{dBm}$ to $5 \mathrm{dBm}$ are recorded. The performance analysis of the HMEH is divided into two; thermal and vibration harvester circuit and RF harvester circuit. These proposed HMEH circuits are modeled, designed and simulated using PSPICE software. Vibration produces AC input and will be converted to DC using a rectifier. A comparator is used to compare the two sources (thermal and vibration) and boost converter is proposed to step-up these small input sources. Meanwhile, due to RF large frequency, the voltage multiplier is practical for both rectify and step up the input instead of the boost converter. LC resonant network is used to amplify low ambient input of RF passively before it goes to 4-stages voltage multiplier. The proposed HMEH able to achieve the output ranges of 2.0 to $4.0 \mathrm{~V}$ with $1 \mathrm{M} \Omega$ load. The results obtained in this research work shows that the proposed design able to produce sufficient voltage for biomedical application requirement which lies between $2.0-4.0 \mathrm{~V}$ from the ambient input of 0.02 to $0.5 \mathrm{~V}$ for thermal and vibration while-9dBm for RF signal.
\end{abstract}

Keywords: Energy harvester, Ultra-low power, Hybrid inputs.

(C) 2016 The Authors. Published by Innovare Academic Sciences Pvt Ltd. This is an open access article under the CC BY license (http://creativecommons.org/licenses/by/4.0/) DOI: http://dx.doi.org/10.22159/ijpps.2016v8s2.15213.

\section{INTRODUCTION}

Nowadays, energy harvester plays an essential role to provide Ultra Low Power (ULP) input source for the wireless device instead of a battery. However, in an implantable application like a pacemaker, the high energy density and small batteries are still used as a conventional energy source. In recent years, researchers proved that the inner ear can be scavenged to generate energy and possible to run the implantable devices. The circuit design technique is important in prolonging the lifetime and reducing the power consumption. By combining energy harvester sources, the low power technique is utilized to recharge the battery continuously for achieving autonomous operation [1]. Many energy harvesting sources like vibration, RF, thermal, solar and wind are obtainable depends on their efficiency, the size of harvester and availability. Energy harvesting of thermal and vibration from the human body are global accessibility and it is demanding widespread attention for implantable devices and powering wearable. The power generated from ambient energy can reach microwatt ( $\mu \mathrm{W}$ ) range and possible to run low power devices. In addition for human vibration, energy can be scavenged from the natural motion of the human chest during breathing [2].

Meanwhile, for RF source, the system will extract ambient power from the radio waves propagation in our surrounding. RF to DC power conversion system is designed to operate in Ultra High Frequency (UHF). For a biomedical application, the industrial, scientific, and medical (ISM) band of 902-928 MHz can be exploited for RF energy harvesting. In this frequency range, RF power is transmitted more efficiently for longer distances and experiences lower propagation losses than higher frequency bands (i.e., 2.4GHz). Importantly, maximum $4 \mathrm{~W}$ effective isotropic radiated power (EIRP) is acceptable by regulatory bodies [3]. Hybrid energy harvesters from previous researchers show a great performance in energy conversion efficiency with the characteristics of small volume, lower work energy and more output energy [4]. Basic block diagram of the proposed hybrid energy harvester is shown in fig. 1.

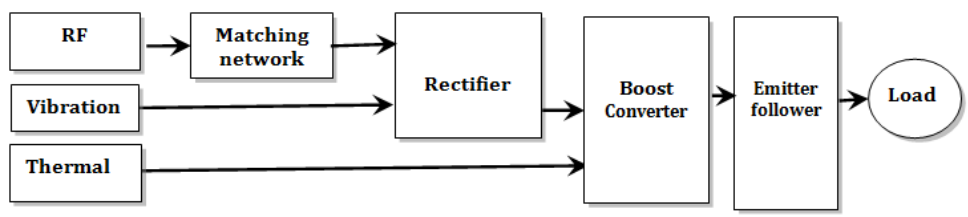

Fig. 1: Block diagram of the proposed hybrid energy harvesting system

\section{MATERIALS AND METHODS}

\section{Hybrid micro energy harvester design}

Hybrid Micro Energy Harvester (HMEH) combines three input sources of RF, thermal and vibration into an individual system to solve the low power problem. It gives sufficient power delivery for the load with the aim to make sure the energy flows incessantly
[5-6]. In this work, we divide the circuit design into two parts; thermal and vibration harvester circuit and RF harvester circuit.

Thermal and vibration harvester circuit design

Thermoelectric generator (TEG) device is used to convert thermal energy into electrical energy based on the See beck effect operation. The electricity will be generated when temperature gradient across 
two conductors are connected together in series. This scenario is applied to the thermocouples that are extensively used for temperature measurements. The output voltage of the TEG is proportional to the number of thermocouples and to the temperature gradient between cold and hot side. For human vibration, it will vibrate at a different frequency, depends on health condition. High frequency will be achieved for those who are in healthy condition.

The rectifier is the first phase in electrical energy harvesting circuit to convert AC input to DC output of vibration. The full-wave rectification with four MOSFETs is to solve the issues of power losses and forward-voltage drop. When conducting it has inferior constant resistances [7] which can make the MOSFETs have low leakage current [8]. The output ripples can be reduced by connecting a large capacitor at the DC side. The power generated from a vibration substrate can be fixed and controlled using the full wave rectifier [7].

Operational amplifier (OP AMP) 741 is used as a comparator to consolidate the input sources of thermal and vibration. The comparator is always used to check and compare the voltages whether have reached the target value of $0.02 \mathrm{~V}$ to $0.5 \mathrm{~V}$. These inputs will be step up to the desired output of 2.0 to $4.0 \mathrm{~V}$ using boost converter circuit. The basic structure of a boost converter is controlled by MOSFET as a switch due to fast switching and high efficiency [1]. The boost converter can be conducted in continuous or discontinuous conduction mode which is marked by the ON and OFF switch. At steady state operation, the current flows endlessly and the current is not allow to flow from the negative side for continuous and discontinuous conduction mode respectively [9]. The switch-mode boost converter capable of generating the lowest input to $1 \mathrm{~V}$ output [10]. To support the boost converter circuit, the Schottky diode of 1 N577 is utilized to avoid a large voltage drop as compared with PN diode [11]. When switching frequency is an increase, a small inductance is used to produce the boost converter with high efficiency and low power losses $[9,12]$. The last stage in this energy harvesting circuit is emitter follower to isolate input circuit from the output load. Schematic diagram for the proposed thermal and vibration harvester is shown in fig. 2 which is designed and simulated using PSPICE software.

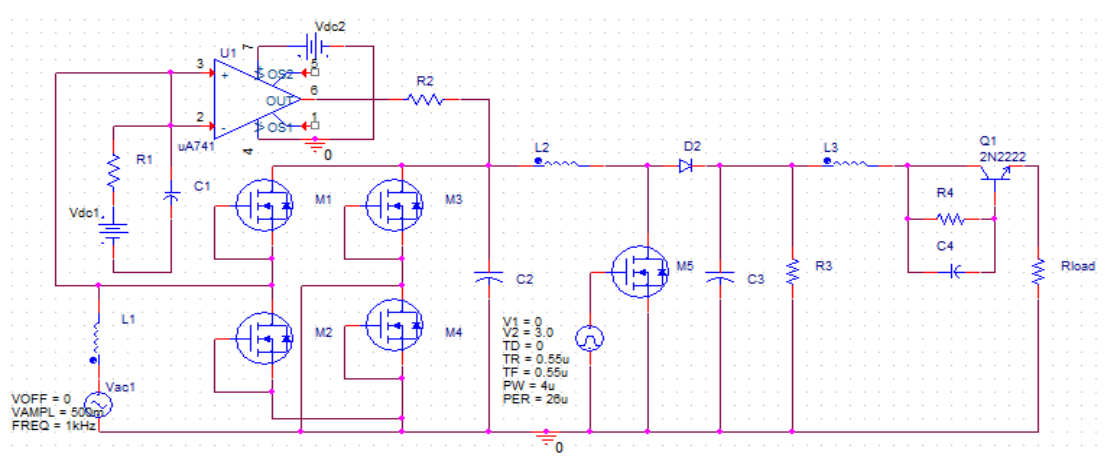

Fig. 2: The proposed thermal and vibration energy harvester circuit

\section{RF harvester circuit design}

Generally, the received energy at the medical implant or any remotely powered devices will be rectified before supplied to any type of applications. Antenna will capture the RF signal, and transfer the extracts power of those signals to the rectifier before converts them into DC voltage [13]. To achieve maximum power transfer to the load, the design should consider impedance matching. This is important not only for optimizing the efficiency but at the same time to perform passive amplification of the input voltage. Voltage amplification is needed to step up the input voltage to a level that can turn on the active elements in the rectifier circuit [14]. The idea of LC resonant network was applied as there will be high dc current flows across the inductor which causes voltage boosting on voltage multiplier input [15].

The AC-DC circuit designed in this paper is based on a Dickson voltage multiplier circuit. Typically, this voltage multiplier able to produce DC output larger than a conventional diode rectifier circuit [16]. The behavior of this converter is not only to rectify the input AC signal but also increase the DC voltage level. With combinations of rectifier MOSFET and capacitors together, the input would be effectively multiplied. Basically, DC output voltage $\left(\mathrm{V}_{\mathrm{dc}}\right)$ is limited by the peak value of sinusoidal input voltage. Additionally, the number of rectifier stages has a major effect on the output voltage since they are directly proportional [17]. Voltage multiplier of four stages has been presented in this paper and the output voltage produce from input as low as- $20 \mathrm{dBm}$ to $5 \mathrm{dBm}$ with level power interval of $5 \mathrm{dBm}$ has been analyzed. The stage capacitances are set to an equal value of $20 \mathrm{pF}$.

Since the input ac signal obtained at the antenna is generally much smaller than diode threshold, previous researchers used lowest possible turn on voltage diode as their rectifying element, for example, Schottky diode [18]. This power converter could achieve high Power Conversion Efficiency (PCE), but the processing cost is quite high and it is not compatible with conventional CMOS technology. Therefore, Schottky diode has been replaced with diode-connected MOSFET. This device will acts as a diode when the drain and gate are short or tied together. An enhancement mode n-channel MOSFET is chosen for this circuit. However, a diode connected MOSFETs still have a constraint as the amplitude voltage of the input RF signal is very low compared to their threshold voltage $\left(V_{\text {th }}\right)$ [19]. Therefore, a bulk modulation technique is applied for the proposed design as in fig. 3 to improve the efficiency and performance of the Diode connected NMOS MOSFET.

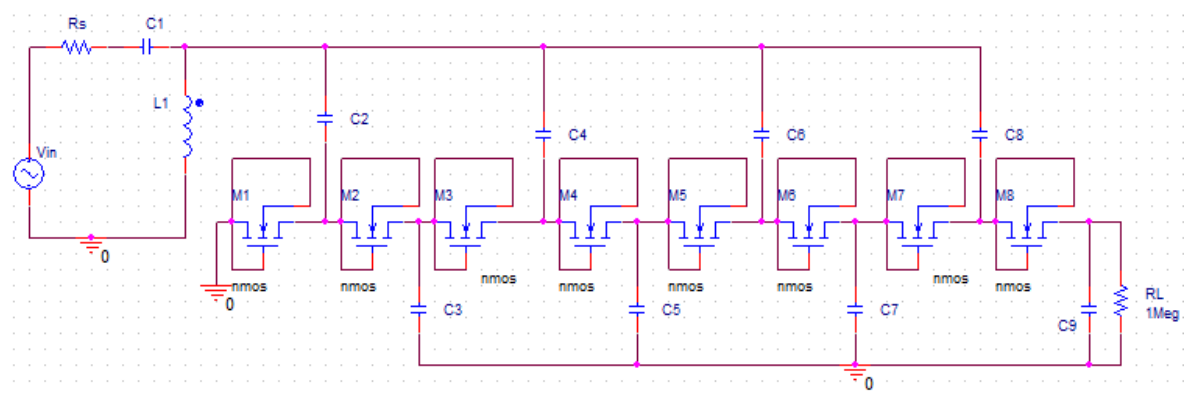

Fig. 3: The proposed RF energy harvester circuit 


\section{RESULTS AND DISCUSSION}

For thermal and vibration harvester, the minimum input is $0.02 \mathrm{~V}_{D C}$ when thermal only exists. While the maximum input is referred to the combination of thermal and vibration. The $0.5 \mathrm{~V}_{\mathrm{AC}}$ is chosen as an input voltage for vibration. The input selection is determined by a comparator using $0 \mathrm{p}$ amp and conducted in positive saturation level to produce desired output. Most of the loads always operate in DC mode but vibration input will generate AC voltage. Therefore, full wave rectifier will be used to convert AC to DC. Fig. 4 shows the simulation result for thermal and vibration circuit using $1 \mathrm{M}$ load resistance. The time ranges of the voltage are set between 0 to 1.8 second (s). It can be observed that the voltage increase directly proportional with time and the maximum output is achieved at $1.8 \mathrm{~s}$. From the simulation, the output voltage of rectifier $\left(\mathrm{V}_{1}\right)$ is approximately equal to $1.5 \mathrm{~V}$. Then, the inputs are integrated with boost converter circuit using $\mathrm{V}_{1}$ as an input. Meanwhile, $\mathrm{V}_{3}$ is a boost converter output and become an input for emitter follower. It is able to achieve approximately $4.5 \mathrm{~V}$ output voltage. $\mathrm{V}_{3}$ is regulated to 4.0Vwhich marked as $\mathrm{V}_{2}$ and it is suitable for biomedical devices.
For RF harvester, the $\mathrm{LC}$ resonant circuit able to amplify the AC input to a level that can turn on the NMOS in the voltage multiplier. NMOS diode width/length ratio is chosen to be as high as $37.5 \mathrm{um} / 130 \mathrm{~nm}$. The capacitor is parallel designed with load resistance to store the output voltage and influence the speed of transient response [17]. By increasing the number of multiplier stages, the output voltage will be increased, but this will reduce current across the load. Then, the charging delay for the energy storage capacitor will be longer. Meanwhile, fewer stages of the multiplier shorten the charging time, but the voltage produced may not be sufficient for powering electronic sensor. From the transient response as shown in the fig. 5, the output voltage is approximately equal to $2.2 \mathrm{~V}$ at the time, $\mathrm{t}$ equals to $130 \mathrm{us}$ which is suitable for biomedical devices. To achieve this voltage, the minimum input power should be- $9 \mathrm{dBm}$ which equals to $112.2 \mathrm{mV}$ for $50 \Omega$ antenna system. fig. 6 shows the output voltage of the harvester when input power is varied from- $20 \mathrm{Bm}$ to $5 \mathrm{dBm}$. At $0 \mathrm{dBm}$ input power, the output voltage equals to $6 \mathrm{~V}$. From the simulation result, the dc output voltage is directly proportional to the input power for $1 \mathrm{M} \Omega$ load resistance. If load resistor is neglected, the voltage will be storing indefinitely on the capacitor.

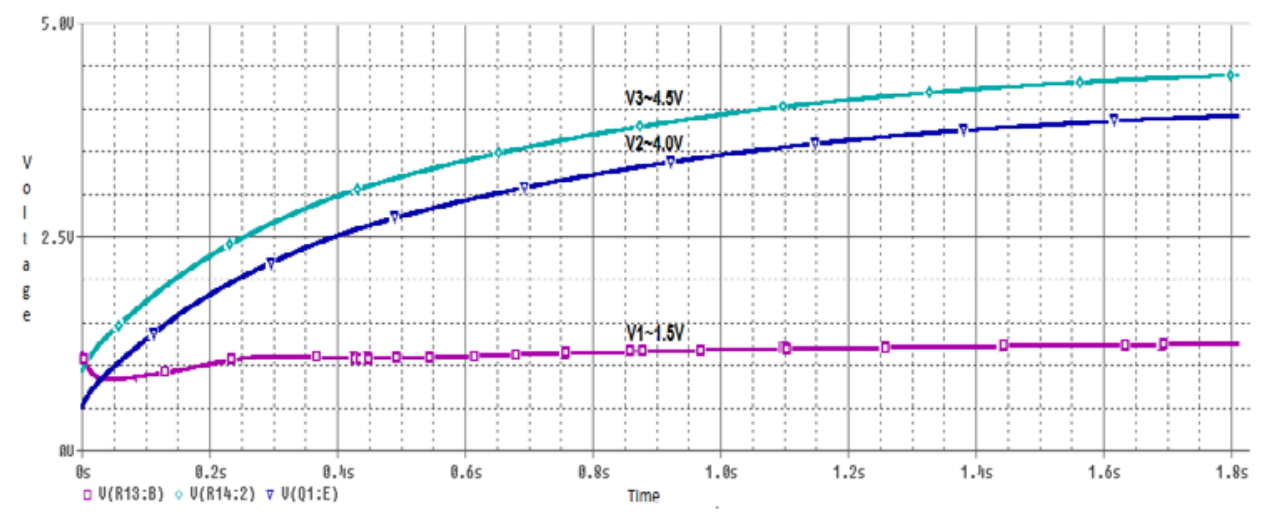

Fig. 4: Output voltage of thermal and vibration circuit

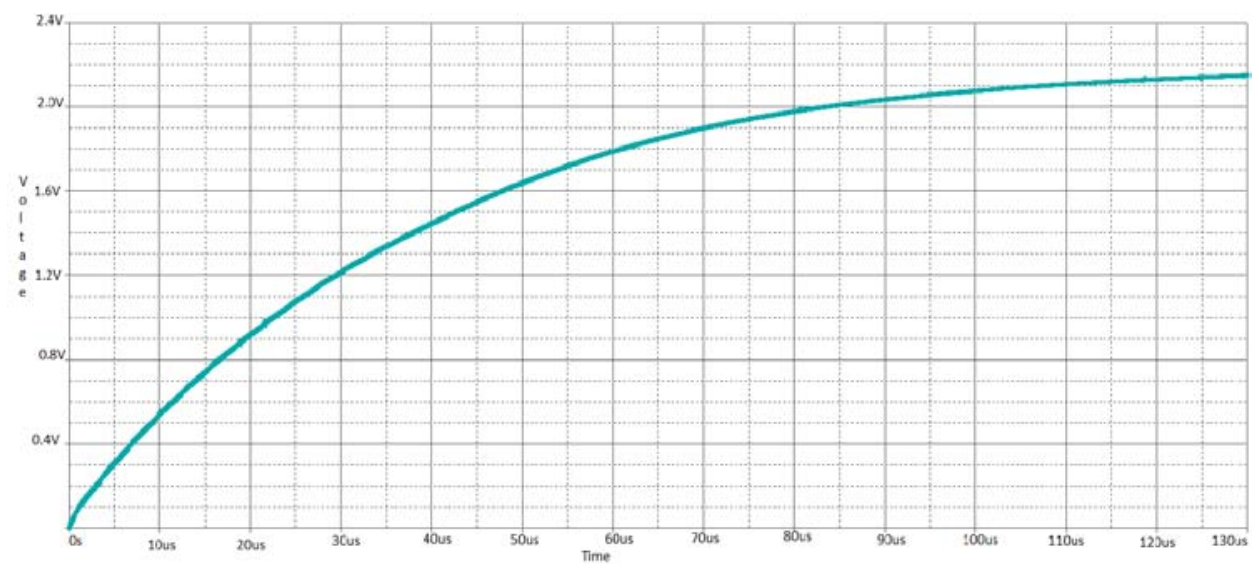

Fig. 5: Output DC voltage of multiplier

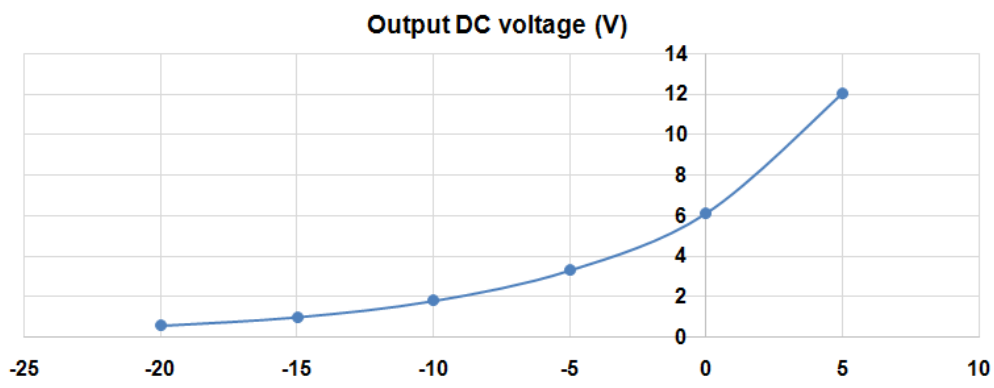

Fig. 6: DC output voltage with varies input power 


\section{CONCLUSION}

The architecture of Ultra Low Power Hybrid Micro Energy Harvester (HMEH) based on RF, thermal and vibration for biomedical application has been presented in this paper. The HMEH is divided into two; thermal and vibration harvester circuit and RF harvester circuit. Thermal and vibration circuit inputs are represented by $0.02 \mathrm{~V}_{\mathrm{DC}}$ and $0.5 \mathrm{~V}_{\mathrm{AC}}$ respectively. The minimum input is set to $0.02 \mathrm{~V}_{\mathrm{DC}}$ if thermal only exists while maximum input is achieved when both of the inputs exist. With operating under $1 \mathrm{kHz}$ frequency, $0.5 \mathrm{~V}_{\mathrm{AC}}$ is rectified to convert $\mathrm{AC}$ to $\mathrm{DC}$ voltage. The proposed thermal and vibration harvester is designed to achieve the desired output of 2.0 to $4.0 \mathrm{~V}$. The simulation shows that the target output of $4.0 \mathrm{~V}$ is achieved with the combination of both inputs. Meanwhile for RF harvester, with input as low as- $20 \mathrm{dBm}$ to $5 \mathrm{dBm}$, the output voltage ranges between $0.57 \mathrm{~V}-12 \mathrm{~V}$. To achieve the target output for biomedical application, the minimum input power required is- $9 \mathrm{dBm}$ which produces $2.2 \mathrm{~V}$. The matching network has passively amplified the input voltage as low as $22 \mathrm{mV}$ to turn on the voltage multiplier MOSFET.

\section{ACKNOWLEDGEMENT}

This research is funded by GUP-2015-021 and FRGS (FRGS $\backslash 2 \backslash$ $2014 \backslash 303 \backslash U K M \backslash 02 \backslash 1$ ) grants from Ministry of Education Malaysia.

\section{CONFLICT OF INTERESTS}

All authors have none to declare

\section{REFERENCES}

1. Carreon Bautista S, A Eladawy, AN Mohieldin, E Sanchez Sinencio. Boost converter with dynamic input impedance matching for energy harvesting with multi-array thermoelectric generators. IEEE J Solid-State Circuits 2014;61:5345-53.

2. M Wahbah, $\mathrm{S}$ Member, M Alhawari, B Mohammad, S Member, $\mathrm{H}$ Saleh, et al. Characterization of human body-based thermal and vibration energy harvesting for wearable devices. IEEE J Emerging Selected Topics Circuits Systems 2014;4:354-63.

3. G Papotto, F Carrara, G Palmisano, S Member. A 90-nm cmos threshold-compensated rf energy harvester. IEEE J Solid-State Circuits 2011;46:1985-97.

4. $\mathrm{H} \mathrm{Yu}, J$ Zhou, $W$ Wang. A new hybrid piezoelectricelectromagnetic micro vibration energy harvester. IEEE Int Conf EDSSC; 2014. p. 1-2.

5. Nor Afidatul Asni Semsudin, Jahariah Sampe, Md Shabiul Islam, Ahmad Rifqi Md Zain. The architecture of ultra-low-power micro energy harvester using hybrid input for biomedical devices. Asian J Sci Res 2015;8:212-24.

6. Michelle Lim Sern Mi, Sawal Hamid Muhammad Ali, S Jahariah, Muhammad Shabiul Islam. Modelling of hybrid energy harvester with dc-dc boost converter using arbitary input sources for ultra-low-power micro-devices. IEEE Int Conf Semiconductor Electronics; 2014. p. 28-31.

7. Yuan Rao, David P Arnold. An input-powered vibrational energy harvesting interfaces circuit with zero standby power. IEEE Trans Power Electron 2011;26:3524-33.
8. Sarker MR, SHM Ali, M Othman, S Islam. Designing a batteryless piezoelectric based energy harvesting interface circuit with 300mv startup voltage. J Phys: Conf Ser 2013;431:1-8.

9. Carlson EJ, K Strunz, BP Otis. A $20 \mathrm{mV}$ input boost converter with efficient digital control for thermoelectric energy harvesting. IEEE J Solid-State Circuits 2010;45:741-50.

10. E Carlson, K Strunz, B Otis. $20 \mathrm{mV}$ input boosts converter for thermoelectric energy harvesting. Symp VLSI Circuits 2009;2:162-3.

11. Semsudin NAA, Sample J, Shabiul Islam M, Rifqi Md Zain A, Berhanuddin DD. Designing a boost converter of micro energy harvester using thermal and vibration input for biomedical devices. IEEE Regional Symposium on Micro and Nanoelectronics (RSM); 2015. p. 1-4.

12. Shafii A Wahab, MS Bhuyan, Jahariah Sampe, Sawal H Md Ali. Parametric analysis of boost converter for energy harvesting using piezoelectric for micro devices. IEEE-ICSE Proc; 2014. p. 525-8.

13. Z Zakaria, NA Zainuddin, MN Husain, MZ Abidin, A Aziz, MA Mutalib, et al. Current developments of RF energy harvesting system for wireless sensor networks. Adv Information Sci Service Sci 2013;5:328-38.

14. B Li, N Goldsman. Voltage doubler design procedure for low ambient RF energy harvesting applications. Int Semicond Device Res Symp 2013;1:1-2.

15. Zulkifli Farah Fatin, Sampe Jahariah, Islam Mohd Shabiul, Mohamed Mohd Ambri. The architecture of ultra low power micro energy harvester using RF signal for health care monitoring system: a review. Am J Appl Sci 2015;212:335-44.

16. Kavuri Kasi Annapurna Devi, Norashidah Md Din, Chandan Kumar Chakrabarty. Optimization of the voltage doubler stages in an RF-dc convertor module for energy harvesting. Circuits Systems 2012;3:216-22.

17. Nintanavongsa $P, U$ Muncuk, DR Lewis, R Chowdhury. Design optimization and implementation for RF energy harvesting circuits. IEEE J Emerging Selected Topics Circuits Syst 2012;2:24-33.

18. Zulkifli Farah Fatin, Sampe Jahariah, Islam Mohd Shabiul, Mohamed Mohd Ambri, Wahab Shafii A. Optimization of RF-DC converter in micro energy harvester using voltage boosting network and bulk modulation technique for biomedical devices. IEEE Regional Symposium on Micro and Nanoelectronics (RSM); 2015. p. 51-4.

19. Shrivastava RD, Deshpande D, Changzhi Li, Gale R. An energy harvesting system using 3-stage voltage multiplier and MPVD charge pump for wireless sensor networks. IEEE Topical Conference on Wireless Sensors and Sensor Networks (WiSNet); 2013. p. 40-2.

\section{How to cite this article}

- Jahariah Sampe*, Farah Fatin Zulkifli, Nor Afidatul Asni Semsudin, Md Shabiul Islam, Burhanuddin Yeop Majlis. Ultra low power hybrid micro energy harvester using rf, thermal and vibration for biomedical devices. Int J Pharm Pharm Sci 2016;8 Suppl 2:18-21 